University at Buffalo School of Law

Digital Commons @ University at Buffalo School of Law

$1-1-1990$

\title{
Dispute Processing and a Longitudinal Approach to Trial Courts
}

Lynn Mather

University at Buffalo School of Law

Follow this and additional works at: https://digitalcommons.law.buffalo.edu/journal_articles

Part of the Courts Commons, and the Litigation Commons

\section{Recommended Citation}

Lynn Mather, Dispute Processing and a Longitudinal Approach to Trial Courts, 24 Law \& Soc'y Rev. 357 (1990).

Available at: https://digitalcommons.law.buffalo.edu/journal_articles/857

(C) 1990 Law and Society Association. Reproduced with permission.

\section{IN COPYRIGHT}

This Article is brought to you for free and open access by the Faculty Scholarship at Digital Commons @ University at Buffalo School of Law. It has been accepted for inclusion in Journal Articles by an authorized administrator of Digital Commons @ University at Buffalo School of Law. For more information, please contact lawscholar@buffalo.edu. 


\title{
A. Dispute Processing-The Paradigm Extended DISPUTE PROCESSING AND A LONGITUDINAL APPROACH TO TRIAL COURTS
}

\author{
LYNN MATHER
}

\begin{abstract}
This article suggests ways to integrate the insights and findings of two rather distinct fields: docket-based, longitudinal studies of trial courts and studies of dispute processing. In particular, I argue that longitudinal research on courts would benefit enormously from the incorporation of concepts and data on dispute processing. For example, instead of taking court cases as the starting point for study, longitudinal research should explore the multistage and transformative nature of disputing. Historical data should also be collected on the nature of the relationships between opposing litigants, on the roles played by participants other than the litigants (lawyers, supporters, audiences, third parties), and on the nature of processes within courts and within alternative community institutions for handling disputes. Longitudinal research can also contribute to our understanding of dispute processing by showing how current processes have been shaped by past use, and how changes in institutions and legal doctrine have influenced the definition and processing of disputes. I also discuss the weaknesses shared by some of the research in both fields, such as a greater concern for process than for outcome, a tendency to ignore political aspects of litigation, and an overemphasis on individual disputing behavior. I conclude by suggesting that longitudinal research on trial courts should pay greater attention to change in ideas about law and to shifting conceptions of right and wrong, cause and responsibility, and problem definition.
\end{abstract}

\section{INTRODUCTION}

THE DISPUTE: Paul and his wife Suzanne have quarreled for years, usually resolving their differences with physical violence. One morning Suzanne burned the toast, and Paul got angry and hit her with the hot frying pan.

DISPUTE PROCESSING IN 1955? Suzanne told everyone her injury was an accident and vowed never again to burn the toast. She did not perceive a "dispute"; after all, Jackie Gleason regularly threatened Alice on TV for her "dumb" actions, and such fighting was quite normal for families.

DISPUTE PROCESSING IN 1970? Suzanne was angry at Paul and called the police to file a criminal complaint

LAW \& SOCIETY REVIEW, Volume 24, Number 2 (1990) 
against him. The police attempted informally to mediate the argument but without success. Suzanne was told that legal action was inappropriate here since it was just a family fight and not a criminal matter.

DISPUTE PROCESSING IN 1985? Suzanne called the police to file a criminal complaint against Paul. The police forwarded her complaint to the local prosecutor, and Paul was prosecuted for assault in criminal court. Suzanne also received support from the local women's shelter about how to obtain a temporary restraining order from the civil court. Paul's criminal case was settled by plea negotiation, with a guilty plea in exchange for a sentence of probation and counseling.

Research on dispute processing can help us understand why this hypothetical dispute was handled as it was in each year. Such research raises questions about the issues involved in the dispute and the cultural views of those issues, the relationship between the parties and the differences of power and resources between them, the nature and accessibility of alternative legal and nonlegal processes for dispute resolution, the roles played by supporters and third-party interveners, and the operational, local meaning of the formal law on assault. With this information we can develop a rich portrayal of disputant choices-fighting, "lumping it," mediation, negotiation, and the threat of adjudication-situated in time and place. But what is missing is an understanding of the dynamic that changes dispute processing over time and that explains how and why the alternatives for Suzanne were different in 1985 than they were in earlier years.

One way to fill that gap is through longitudinal research on the use of trial courts that is sensitive to the broader social and political context of courts. Such a study would show an increase in criminal and civil court filings involving complaints by wives against husbands for violence. Further research could link the court data to broad socioeconomic and political changes (e.g., more working women and greater political power for women) or to specific policy changes (e.g., new laws specifically prohibiting spouse abuse, successful class action lawsuits against police by battered wives, and policy announcements from prosecutors' offices regarding domestic violence).

Longitudinal analysis of the use of courts by battered wives could be further improved, however, by attention to some of the factors important for research on dispute processing. For example, one could examine changes in the support networks for the parties (e.g., women's shelters and hotlines), changes in the popular culture (e.g., mass media portrayals of husband/wife fighting and documentaries on spouse abuse), changes in language (e.g., from "family fights" to "battered wives" and "domestic violence"), and changes in the demographics and training of legal personnel (e.g., 
more women police officers and prosecutors, and new police training programs).

While the fields of dispute processing and longitudinal studies of trial courts have each grown enormously in recent years, it is striking that there has been so little linkage or integration of the two. In this comment I would like to suggest possible avenues of convergence. I will first summarize major contributions of the dispute processing literature and then discuss ways in which the two literatures might complement each other, and specifically how longitudinal research might help to answer some of the critiques of dispute processing and how insights from the disputes field could inform longitudinal research on courts.

\section{LESSONS FROM DISPUTE-PROCESSING RESEARCH}

Anthropologists were among the first to use disputes and processes of dispute settlement as a framework for research on law. ${ }^{1}$ The challenge of developing theory about law based on comparative data demanded a focus that would cross-cut societies and their individual moots, courts, and other institutions (Nader and Todd, 1978). The result was an emphasis on processes of dispute settlement with an interest in the determinants and consequences of different modes of dispute settlement and attention to the "full socio-cultural context of the dispute cases" (Gulliver, 1969a: 13). Continuing in this research tradition, Abel (1973) developed a theory of dispute processes based upon role differentiation of the third-party intervener both with respect to the dispute institution and to the larger society. Recent research on dispute processing has developed several major themes: the role of courts in handling disputes, the importance of relations between the parties for dispute processing, the transformation of disputes, and the alternative strategies and processes for dispute resolution. The incorporation of this work in the longitudinal analysis of trial court usage is badly needed.

First, longitudinal studies should recognize the multivariate and multistage nature of disputing instead of taking court cases as the starting point for study. Perhaps the most common image of dispute processing, presented by the Civil Litigation Research Project (Miller and Sarat, 1980-81), is of a disputing pyramid in which there is a wide base of grievances at the bottom. Grievances may move up the pyramid as they are voiced as claims, and, if rejected by the opposing party, they become disputes. At the very top-the tip of the proverbial disputing iceberg-are those disputes filed as legal cases in court. Clearly, courts are used to resolve only a very few of the disputes in society, and a central task is to understand how courts become involved in some conflicts but not

1 See, e.g., Llewellyn and Hoebel (1941), Nader (1969a), Gulliver (1963), and Nader and Todd (1978). 
others, which involves looking at individual features of conflicts as well as characteristics of the court, its alternatives, and the society (Sarat and Grossman, 1975). In taking this disputes-focused approach, one places courts in their wider context, and the dispute becomes "a conceptual link between law and society" (Trubek, 1980-81a: 494).

A problem for this approach in terms of understanding the role of courts in society is that the central concept-dispute-is not a single event easily identified but rather a stage in a social relationship (Abel, 1973). Further, while scholars stress the importance of knowing what occurs prior to the dispute, they disagree in their definitions of the predispute stages and of the dispute itself. ${ }^{2}$ The earliest stages of the disputing process have received particular attention from scholars interested in how and where claims are generated. Felstiner, Abel, and Sarat (1980-81: 634-35) identify the stages of the disputing process as naming, or experiencing an injury or problem; blaming, or attributing the injury to the fault of another party; and claiming, or confronting the opposing party and asking for some remedy. ${ }^{3}$

A central question for investigators of the disputing process is: What moves a grievance from one stage to another? Put another way, What explains variations among disputes? Why do some emerge at the top of the pyramid in court while others do not? In the economic model of Cooter and Rubinfeld (1990), the rational self-interest of the disputing parties is the driving force; they each try to maximize their own gain through bargaining, and it is only when the bargaining fails that the dispute moves on to the next stage. Other research points to different factors at work: the type of grievance (Miller and Sarat, 1980-81); the goals, resources, and capabilities of the parties (Galanter, 1974a); the involvement of supporters or an audience (Mather and Yngvesson, 1980-81); cultural attitudes toward law and conflict (Engel, 1984; Merry and Silbey, 1984); the role of lawyers (Rosenthal, 1974; Johnson, 1980-81); characteristics of the third party (Abel, 1973) or the disputing forum (Yngvesson and Mather, 1983); the availability of alternative processes (Silberman, 1985); and the relationship between the parties (Macaulay, 1963; Collier, 1973). ${ }^{4}$

Second, longitudinal studies should explore the nature of the

2 Compare, for example, the definitions of Nader and Todd (1978: 14-15), Gulliver (1979: 75), Abel (1973: 227), and Miller and Sarat (1980-81: 527-29).

3 Other categorizations of stages in the disputing process are provided by Silberman (1985) and Boyum (1983), but compare Cooter and Rubinfeld (1990). I have some trouble with the distinction between "naming" and "blaming," since definitions of problems, as social and linguistic constructs, tend to join facts and norms (Mather and Yngvesson, 1980-81; Comaroff and Roberts, 1977). Thus the very act of naming incorporates the blaming. Or, as Silberman (1985: 4) writes, "there is no reason to believe that the cognitive and evaluative aspects of such events are separable."

4 For further discussion of these and other factors, see Sarat and Grossman (1975) and Nader and Todd (1978). Silberman (1985) shows how certain 
relationship between opposing parties in court. Scholars have long argued that individuals or organizations with close, continuing relations are less likely than strangers to use legal norms and procedures to settle their disputes. Out of a concern to preserve their relationship, parties with such ongoing ties-whether social, interpersonal, or economic-prefer to handle their grievances in nonlegal or unofficial ways. ${ }^{5}$ A macro version of this view of continuing relations and the law underlies much of the research on litigation and social change. That is, since related parties are unlikely to use law for dispute settlement, then as close personal and social relationships break down, one expects an increase in the use of litigation to resolve disputes, a proposition that has been explored both through comparative and longitudinal research. ${ }^{6}$

Although the continuing relations argument sensitizes us to the importance of relations between parties for their disputing behavior, it does not mean that we should ignore the use of law by those who are closely related. Yngvesson (1985a) summarizes empirical work, which is often overlooked, on the use of legal and other official processes by those with ongoing social ties, showing the significance of such use for defining and changing the very basis of relationships. "Law and courts shape ongoing relations," writes Yngvesson (ibid., p. 62), especially when relationships are viewed over the long term and when attention is paid to strategic and political aspects of the disputing process. In a retrospective, Macaulay (1985) reiterated his basic argument on the marginality of contract law for long-term, continuing business relations but also added several interesting examples of cases in which litigation did provide a basis for the renegotiation of the terms of the relationship (see Blegvad, 1990).

A third contribution of research on dispute processing to longitudinal, docket-based analysis begins with the observation that a case as it appears in court may not reflect the underlying dispute

factors may have a greater effect at one stage of the disputing process than at others.

5 The continuing relations argument is found in some of the earliest and most significant works in the law and society field. Macaulay (1963) showed that people in business avoid contract law in planning exchanges and seldom use legal sanctions to settle disputes, believing that such intervention would disrupt the ongoing business relationships. Nader (1965), Gulliver (1963), Collier (1973), and other legal anthropologists found that among kin groups or within small, face-to-face societies people prefer to resolve disputes through informal, compromise-oriented procedures to preserve harmony within the group. Gluckman (1955) made this point in terms of multiplex as versus single-interest relationships, arguing that disputants with multiplex relations use processes that emphasize conciliation and that are directed toward the maintenance of continuing relations. Sociologist Black (1970) pointed to the importance of relational distance on the mobilization of law based upon his finding that offenses were less likely to be labeled crimes if they occurred between closely related people such as family or friends; he later expanded this argument in his 1976 book.

6 See Sarat and Grossman (1975), McIntosh (1983), and Munger (1988). 
or even the initial conflict. A dispute is not a singular, identifiable entity that moves without change from one stage to another in the process of attempted resolution. Instead, disputes change-or are transformed-as different participants assert their own interests and perspectives on the conflict. Thus "what a dispute is about, whether it is even a dispute, and whether it is properly a 'legal' dispute, may be central issues for negotiation in the disputing process" (Mather and Yngvesson, 1980-81: 776-77; see Santos, 1977). Longitudinal research must take this transformation into account when considering the type of dispute as recorded in court dockets.

A transformation of a dispute is a change in its form or content. It includes changes in the identity or number of parties, the scope and number of issues, and the objectives of the participants involved in a dispute (Felstiner et al., 1980-81), or change in the conceptual framework for viewing the dispute (Mather and Yngvesson, 1980-81). A focus on the normative framework and definitions of a dispute reveals the political aspects of disputing and is especially useful for linking "routine processes of conflict management and broader considerations of legal order and change" (Yngvesson and Mather, 1983: 64). When a dispute is "expanded"-rephrased in terms of a new normative framework-it raises a challenge to the established normative order. The challenge may easily be contained by "narrowing" the dispute into a previously established category, or expansion may lead directly or indirectly to legal change (Mather and Yngvesson, 1980-81). Change may result from the appellate judicial process, the mobilization of public opinion, the formation of an interest group, the attention of legislative or other political officials, or even through an increase in further litigation. Longitudinal studies should explore all of these political processes as possible explanations of changes in a particular type of trial court litigation.

A fourth contribution of dispute processing research is its recognition of the importance of participants other than the litigants-representatives or supporters of the litigants, a broader public or audience, or a third party such as mediator, arbitrator, or judge-in shaping the process of dispute transformation (Mather and Yngvesson, 1980-81; Felstiner et al., 1980-81; Fitzgerald and Dickins, 1980-81; Yngvesson and Mather, 1983). Lawyers as representatives of the disputants, as specialists in the language of the law, and as actors with their own interests are clearly important agents of dispute transformation. Interest groups often sponsor test cases, thus transforming the grievances of individual litigants into a conflict that furthers the larger political interest of the group. An audience plays a special role in dispute processing by reinforcing particular views of a case and setting up expectations for the outcome. ${ }^{7}$

7 Audience expectations may significantly constrain or influence the ac- 
Trial court judges transform disputes when they redefine issues under consideration, create new alternatives for action, or add or subtract parties to the case. Not only the judge but also the entire institution of the court can change a dispute to fit its own organizational, bureaucratic, or political needs; Seron (1990) argues that just as the individual motivations of litigants affect the input and outcomes of courts, so do court organizational practices influence how cases are resolved. Consideration of the transformation of disputes thus highlights the significant roles of participants other than the disputants. It also shows the need to distinguish carefully and identify the object of the dispute and the structure of the conflict as it exists at each stage of the process, rather than assuming that these do not change. ${ }^{8}$

Finally, courts may embody several processes of conflict resolution and be situated among institutions providing still other processes. Scholars have explored the empirical differences in processes such as negotiation, mediation, arbitration, or adjudication; the determinants of the choice of process; and the relation between processes of conflict resolution and the social order (Fuller, 1978; Strauss, 1978; Gulliver, 1979). Longitudinal research often builds implicitly on a social development model in which dispute processes become more formal and coercive as societies increase in complexity (for summary of the model, see Friedman, 1983). Investigators should explore, however, the full range of processes actually used by disputants at each point. A community's ideology of conflict management may in fact be quite different from the diverse strategies and processes of conflict management actually employed (Yngvesson and Mather, 1983).

Comparison between alternative forums within a society has led to suggestions about the consequences of process for dispute outcomes. McEwen and Maiman (1984), for example, found that defendants in small claims disputes were much more likely to comply with mediated agreements than with adjudicated judgments (but cf. Vidmar, 1984; McEwen and Maiman, 1986). Inter-

tions of those involved in the dispute, a point perhaps illustrated by Burstein's (1987) research. His comparison of equal opportunity litigation by four minority groups shows greater federal resources for support and a more favorable win-loss ratio in complaints of racial or sexual discrimination than in complaints of discrimination based on religion or national origin. Although the law is the same for all four groups, I would argue that the audience is not; that is, both a broad public and a relevant public have been far stronger and more attentive to racial and sexual discrimination than to discrimination on other grounds.

8 To use the language of strategy, the litigation process should not be seen as one continuous bargaining game (as suggested by Cooter and Rubinfeld, 1990) but rather as a sequential series of bargaining games under different institutional structures and with different sets of participants and preferred solutions. Depending upon the interaction and roles played by litigants, lawyers, other supporters, the audience, and the judge, the feasibility of arriving at different alternatives may change, thus presenting a series of games. 
estingly, comparison between forums often reveals the diversity of actions included within a single label such as "mediation" or "adjudication." That mediator strategies may vary greatly has been noted by Gulliver (1979), Silbey and Merry (1986), and McEwen and Maiman (1986). Indeed, "in particular types of cases some mediators may judge and some judges may mediate" (McEwen and Maiman, 1986: 443). Moreover, the element of coercion that is so integral to adjudication is also found in mediation (Shapiro, 1981; Merry, 1982). In view of the tremendous variation found within each of these processes and the inevitable mixture of elements of mediation and adjudication, some question the usefulness of sharp distinctions between mediation and adjudication (Shapiro, 1981; Yngvesson and Mather, 1983).

Longitudinal work is beginning to pay more attention to the nature of processes found within trial courts. In research that is reported in this issue, Padgett (1990) analyzes changes over time in the different forms of plea bargaining in criminal court; Seron (1990) discusses a shift in the federal courts from adjudication to more routine administration, but also notes that the analytic distinction between the two may be blurred in actual practice; and Ietswaart (1990) summarizes the conceptual problem faced by the European Working Group in identifying what counts as "litigation" for purposes of comparative research. She proposes that the term "litigation" be reserved for disputing before public third parties (i.e., adversary disputes in court), while the term "court caseload" would include the totality of what courts do-that is, administrative case processing as well as litigation. In their empirical work in both fields-longitudinal research and dispute processing-scholars have been somewhat frustrated by an inability to delineate clearly alternative modes of handling disputes.

\section{POTENTIAL CONTRIBUTIONS OF LONGITUDINAL RESEARCH ON TRIAL COURTS TO DISPUTE PROCESSING RESEARCH}

Dispute processing research has shown the importance of the social context of disputes, the stages and factors involved in the emergence and attempted resolution of disputes, the consequences of redefining disputes, and the range of alternative processes and institutions for handling disputes. However, the field has not been without its weaknesses, 9 some of which could be addressed through longitudinal research. For example, dispute processing research often takes a static and ahistorical approach, portraying a rich picture of disputant choices among alternative modes of dis-

9 For critical discussions of dispute processing see Fitzgerald and Dickins (1980-81), Lempert (1980-81), Kidder (1980-81), Cain and Kulcsar (1981-82), Merry and Silbey (1984), and Menkel-Meadow (1985). 
pute settlement fixed at one point in time. ${ }^{10}$ But while we understand the basis for these choices, we know little of the origins of alternative modes of settlement and how current perceptions of them have been shaped by past use. "What we do need to know is how the mechanisms for dispute processing, both formal and informal, got created, modified, and incorporated into the strategies of competing interests . . . [and how] existing institutional forms . . . reflect previous battles" (Kidder, 1980-81: 724). Answering this need is precisely where longitudinal research can be useful. Studies could explore the sociopolitical development of various institutions for handling conflict, and how and why the use of these institutions has changed over time: Longitudinal data could also chart the generation and emergence of new grievances and disputes that have entered the legal system (Miller and Sarat, 1980-81: 565).

The longitudinal view may also help to identify the role of actors-such as the state, trial courts themselves, or other institutions-that case studies and ahistorical research tend to overlook. Work on dispute processing has been criticized for its inattention to the institutions that process disputes and to the laws that influence settlement. Lempert (1980-81: 708) suggests, for example, that understanding dispute-settlement institutions should be " $a$ starting rather than an ending point" for research, and Fitzgerald and Dickins (1980-81: 702) ask in their critique, "Is the context overwhelming the law?" In a sense, the inattention to law and institutions can be simply explained as overreaction: In taking a broader look at disputes, scholars were reacting against a body of work that centered narrowly on courts and legal doctrine, so it is not surprising that those central features of an earlier paradigm became more peripheral concerns in dispute processing research. As the field has matured, there has been greater recognition of the importance of these once central concerns. For instance, in responding to criticism of the disputes-focused approach, Trubek (1980-81b: 744) acknowledged the need for research on "how courts, dispute processing options, and legal doctrine itself affect both the emergence and the suppression of disputes." Longitudinal research can be very useful on this point by exploring the impact of changes in institutions and legal doctrine on the definition, processing, and outcomes of disputes.

\section{SHARED PROBLEMS}

Many studies with a disputes-focused approach share certain weaknesses with longitudinal research, including an overemphasis on process to the exclusion of outcomes, a failure to examine the

10 Some dispute processing research has specifically attempted to incorporate a dynamic view of conflict management in society. Emphasis on transformation in the normative framework used to define a dispute provides a linkage between the micro picture of individual disputing and the macro view of law, social order, and social change (Mather and Yngvesson, 1980-81). 
political significance of dispute processing due to the lack of an underlying theory of social conflict, and a narrow focus on choices of individual litigants.

First, dispute processing studies have been overly concerned with the process of handling disputes and have paid too little attention to dispute outcomes. When Menkel-Meadow (1985: 39) makes this point, she calls especially for more discussion of the quality or utility of outcomes, while Lempert (1980-81: 707) simply notes the confounding of outcomes and output and the inaccuracy of using court decisions as measures of party outcome (since, for example, the losing party does not always comply with the decision). Later in the same article, Lempert (ibid., pp. 711-14) argues for research on the relation between the perceived legitimacy of law and normal processes of dispute settlement. In their critique, Fitzgerald and Dickins (1980-81: 689-91) also suggest that research on disputing should include a number of important features of dispute outcomes, such as changes in the parties' prestige, status, and power; the impact of the dispute on the relationship between the parties; and changes in outlook of the disputants.

Longitudinal studies of court usage have also shown more concern for process than for outcome. Scholars have measured litigation rates to assess change in the use of courts for handling disputes, comparing rates over time, across regions, and for different types of disputes. Less often do we find historical work on the outcomes of cases and a recognition of the feedback loops whereby the outcomes of cases shape future litigation. The economists have pursued a version of this point, however; Cooter and Rubinfeld (1990) summarize the argument that law is "market-driven," meaning that "inefficient" laws (and presumably judicial decisions) are more likely than efficient ones to lead to an increase in litigation. Other than in economics and in political science studies of the impact of Supreme Court cases, most sociolegal studies have not addressed the question of the impact of case outcomes in trial courts.

Galanter (1983b: 118) has suggested that instead of looking at "the centripetal movement of cases into courts," we should assess the "centrifugal flow of influence" outward from courts and the impact of legal messages on society. This view, as Engel (1985: 103-4) comments, returns law and society research full circle back to a concern for legal doctrine, but now with greater attention to linkages between judicial decisions and processes of conflict resolution. "Doctrine" does not just refer to the narrow rulings of appellate courts, however, but should be taken much more broadly to include all "legal messages": court rulings (appellate and trial), patterns of negotiated dispositions, meanings attached to different kinds of cases (including those that are both accepted and rejected by the courts), and the ideas about law and social problems that are communicated by legal personnel. 
A second problem with much of the disputing literature is that, as Kidder (1980-81: 719) writes, "the notion of dispute settlement has . . . been decidedly apolitical." There is a functionalist assumption in this body of work that disputes upset the social order and that mechanisms such as courts should resolve disputes and restore order (Cain and Kulcsar, 1981-82). Viewing dispute behavior solely as disruptive stands in contrast to a concept of litigation as a form of political participation (Zemans, 1983) or to a view of dispute strategy as a political vehicle for changing or maintaining the normative order (Moore, 1972; Kidder, 1980-81; Mather and Yngvesson, 1980-81). All too often, disputing research ignores the macro social and economic forces that structure processes of disputing and thus fails to address the relation between disputes and conflict (Menkel-Meadow, 1985). When disputes are seen as quarrels and grievances, there is a tendency somehow to forget their link to law and the norms of the state. Arguments may be over resources or over values-who's right and who's wrong-but whenever they involve public third parties, they are likely to involve collective values, political processes, and the possibility of some form of coercion.

Studies that compare litigation rates over time with various socioeconomic trends also often ignore the political aspects of litigation. That is, courts are viewed simply as passive receptacles for conflicts that bubble up from society in times of social or economic stress. This view is empirically inaccurate and theoretically misleading. Courts are active vehicles of law and the state, and they can (and do) do a great deal to shape the nature and amount of litigation. Further, in his critique of the functionalist view of litigation, Munger (1988) shows how the use of courts is a function of strategy and of litigation capacity. Longitudinal studies of trial courts need to understand the political uses of courts and to situate courts within a changing political context. In an essay in this volume, Seron (1990) develops this same point, observing the irony of historical research on litigation trends that ignores the history of political modification of court processes. More recent longitudinal studies have in fact begun to incorporate political factors in their analysis. McIntosh (1983), for example, in his analysis of litigation rates, includes measures of court capacity and political context. Also in this volume, Heydebrand (1990) shows how policies and actions of the federal government significantly determine patterns of litigation in the federal courts, and Monkkonen (1990) argues for a view of local criminal courts as part of the applied level of the state. Padgett's (1990) study of plea bargaining in the federal courts investigates both the process and outcome of liquor law violations over time, and builds into the analysis changes in the number of judges, differences in judicial backgrounds, and public opinion toward Prohibition.

Finally, both bodies of research-dispute processing and longi- 
tudinal approaches to litigation-suffer from an overemphasis on individual disputing behavior. Individuals are seen as the key players, acting on their grievances and strategically seeking third parties to aid in resolving conflict. In Kidder's (1980-81) critique of disputing research, he relates the individualistic bias of a disputes-focused approach to Western legal assumptions about the primacy of individuals and their legal rights and to the influence of these assumptions on the work of legal anthropologists. Seron (1990) extends the same critique to longitudinal studies of patterns of litigation, remarking on the individualistic, reductionist bias in which questions of social and legal conflict are simply reduced to one of individual motivation and to individual litigious behavior. When assuming this individualistic focus, sociolegal research has often ignored the constraining web of interactions and linkages between disputants and others-whether family, neighbors, lawyers, other supporters, or those watching the conflict. Even in modern Western litigation, it makes little sense to develop an approach based on individual actors when so much litigation involves organizations, thus requiring negotiation of conflict within the organization about how to deal with the opposing party. Kidder (1980-81: 725) emphasizes the group context of disputes and points out that individuals may "become involved in disputing as agents of collectivities" and that individual actions may be "shaped primarily by the internal dynamics of groups to which they belong."

Merry and Silbey (1984) find yet another problem with the individualistic slant of disputing analysis: When disputing is seen as rational choice making and as essentially instrumental behavior, then one underestimates considerations of cultural norms and values; instead, disputes should be seen as "cultural events," with the recognition that ways of dealing with them "derive from habits and customs embedded in social groups and cultures" (ibid., p. 157). They argue that studies of dispute processing must be broadened beyond rational considerations of strategy to include normative elements of culture-beliefs, symbols, and values-as essential components of dispute behavior. Engel (1984) makes this point convincingly in his empirical study of ideology and litigation in Sander County, and it is interesting that the critique is proving useful in some longitudinal research on litigation. Bergstrom (1988) attempted to explain the rise of personal injury litigation at the turn of the century in New York City by industrialization, a rapid increase in injuries, a greater need for help by injury victims, or change in the legal process (changes in either tort doctrine or accessibility of courts). Finding none of these explanations satisfactory, Bergstrom turned to changes in popular consciousness about cause and responsibility. He concludes that conceptual change-_a change in ideas"-is the most promising explanation for the rise of litigation at that time. This conclusion is an important one, inviting a shift in research toward ideology and culture. 


\section{CONCLUSION}

Future research on trial courts and social change should, I think, pursue two major avenues of inquiry. On the one hand, there should be greater attention to ideas about law and shifting conceptions of right and wrong, cause and responsibility, and problem definition. On the other hand, when examining the changing use of courts, there should also be greater attention to the context of disputing and to the nature of alternative institutions and processes for handling disputes.

A number of scholars have identified a focus on ideology as a promising approach to understanding law and social processes. Special issues of the Legal Studies Forum (1985) and the Law \& Society Review (1988) explore, for example, how judicial impact can be understood in terms of the changing legal consciousness of a community (Brigham, 1985); a view of law as social practice (Silbey, 1985), with legal and social practice inseparable and reciprocally constitutive (Sarat, 1985); the conceptualization of sociolegal relations in the ideology of mediation (Harrington, 1985); and the nature and operation of legal ideology in different neighborhoods and courts (Merry, 1985; Yngvesson, 1985b). Longitudinal research could draw on this approach to investigate how law embodied a particular set of ideas and beliefs at different points in time.

By identifying a change in ideas as critical to an observed increase in personal injury litigation, Bergstrom (1988) invited inquiry into the nature and development of legal ideology. Using his study as an illustration, I suggest that further research focus on the cultural and political context of this change. What was the context, particularly the political setting, for this shift in thinking about personal injury? What were the sources of empowerment that facilitated jurors' opposition to judicial decisions? How were other institutions, such as schools, industries, and churches, changing or maintaining their social practices? Who were the popular heroes, and how did the media portray conflicts and law? What language was used to describe accidental injuries, and how did the legal language correspond to more general discourse? Attention to the shifting symbols, beliefs, and meaning attached to personal injury law could improve our understanding of injury victims' increased use of courts.

A second path for improving longitudinal research on trial courts is to apply some of the insights of dispute processing to gain a better understanding of how and why disputes end up in courts. This approach involves gathering a wider range of data than is typically found in longitudinal studies. First, one would examine the various modes of dispute settlement seen as alternatives to trial courts as well as the nature of the trial court itself at different times. What were the processes within different institutions? 
Who were their staffs, and how were they related to different factions or groups within the community? What was the nature of connections between courts and other centers of political power? Second, instead of organizing disputes by their subject matter in conventional legal categories, consider organizing them by nature of the disputing parties. That is, who were the parties? What was their relation to the legal system (e.g., in terms of political connections, previous litigation experience, and resources)? Did individuals from certain families or areas of town regularly use of courts? What was the nature of the relationship between disputing parties? Third, explore the meaning and context of the case itself, rather than taking it as a given. What social, cultural, and political understandings were reflected in particular case labels? What alternative conceptualizations were available to characterize specific incidents or problems, and what influenced the choice of alternatives? Fourth, enlarge the focus of research beyond the litigants and the judge to include others involved in the disputing process. Were lawyers involved? If so, what was their social and political identity, and what was their fee structure? How were groupsfamily, ethnic, class, political, or organization-involved in individual disputes? What was the nature of any publicity about cases?

Gathering these kinds of data is admittedly difficult and thus a formidable challenge for historical research. Despite the difficulties, however, this approach promises a view of litigation that is richer and more complete than much of the current literature. In conjunction with study of law and ideology, longitudinal studies of dispute processing and courts can greatly contribute to a better understanding of law and social change. 